\title{
PRODUCTIVITY ASSESSMENT AND ITS IMPROVEMENT STRATEGIES FOR SMALL METAL WORKSHOPS
}

\author{
M. M. A. Khan ${ }^{1}$, M. A. Islam ${ }^{1}$, A. F. M. Salahuddin ${ }^{2}$ and M. Iqbal $^{1}$ \\ ${ }^{1}$ Department of Industrial and Production Engineering \\ ${ }^{2}$ Office of Registrar \\ Shahjalal University of Science and Technology, Sylhet-3114, Bangladesh. \\ *E-mail: muhshin-ipe@sust.edu
}

\begin{abstract}
A case study research was conducted with a view to assess the impact of five factors such as man, machine, material, money, and safety on productivity. The scope of this study was limited only to small metal workshops, which produces customized independent products. 18 case studies were performed based on selected workshops of different categories (welding shops, repair shops, sheet metal shops). Total Productivity Model (TPM) has been used as the theoretical base of the research model. It has been identified that insufficiency of skilled workers, improper utilization of materials, inefficient inventory control, ineffective safety package etc., are the most critical obstacles to productivity improvement in terms of product and material and hence to the overall productivity improvement of the organization as a whole. Some productivity improvement strategies made on the basis of the observations and analysis are also included in this paper.
\end{abstract}

Keywords: Assessment, Productivity, Total Productivity Model (TPM), and Small Metal Workshops.

\section{INTRODUCTION}

The workshops have been emphasized from time to time with a view to create the opportunity of low investment with high potentiality for employment generation. Economically small and cottage industries provide employment for thousands of unemployed workers and in this context, engineering workshops can contribute a lot. These workshops provide some essential service, particularly in repair and maintenance of productive equipments and machineries ${ }^{1}$. To some extent, they produce finished products that in turn contribute to manufacturing units as a whole.

Small-scale industries like the workshops play a significant role in the growth of our economy. It contributed $10.5 \%, 10.9 \%, 11.3 \%, 11.3 \%, 11.1 \%$ and $11.55 \%$ to GDP in the fiscal years of 1992-93, 1993-94, 1994-95, 1995-96, 1996-97, and 1997-98 respectively². Besides, Bangladesh used to import its maximum (almost $100 \%$ ) equipments, tools and auxiliaries from abroad in exchange of large amount of foreign currency ${ }^{3}$. The workshops can meet our local demand by producing these equipments and other spare parts locally ${ }^{1}$, and therefore, can decrease the dependency on imported equipments and auxiliaries. Moreover, these workshops could also export them to global market satisfying the customer needs.

It is well known that economic growth, as a means to enhancing the welfare of people, depends both on the use of factors of production such as capital, material and labor, and the efficiency in resource use, often referred to as productivity ${ }^{4}$. However, at a given combination of technology and management, a firm may not be able to achieve the expected maximum productivity due to inefficient utilization of the input factors ${ }^{5}$. Besides, the ecology-oriented manufacturing and $5 \mathrm{~S}$ focusing are also considered to be two proven tools in attaining the organizational goal nowadays ${ }^{6}$. That is why; to achieve expected level of productivity of small metal workshop, improvement of total production, effective utilization of input factors, application of appropriate technology and development of effective management have to be emphasized $^{5,7}$.

\section{RESEARCH METHODOLOGY}

Case study was chosen as the research strategy to fulfill the objective of the research. This study was conducted on 18 selected workshops of different categories (welding shop, repair shop, sheet metal shops) located mainly in two commercial cities in session 2004-05. Survey and interviews have been used as the potential data collection techniques. In this study, five input variables (man, machine, material, money, and safety) were considered as per the research objective. Total Productivity Model (TPM) has been used as the theoretical base of the research model.

\section{Theoretical construction of the research}

There are various approaches to measure productivity in manufacturing organizations. Normally, economist, engineers, managers, and so on consider different approaches in measuring productivity at the firm level. The choice of the productivity approaches depends on the nature and aim of the study under taken ${ }^{8}$. In this study, based on the objective and the type of the organization considered, a model has also been selected to measure total productivity as well as the individual product and material productivity. However, David J. Sumanth first developed the model considered. This model is also defined as Total Productivity Model, (TPM) and is used as a total productivity measure and a set of partial productivity measures ${ }^{9}$. Total productivity, as defined in the TPM, is

\begin{tabular}{ll}
\hline Nomenclature \\
$\mathrm{t}$ & current period \\
$\mathrm{TPF}_{\mathrm{t}}$ & total productivity of the firm in time period, $\mathrm{t}$ \\
$\mathrm{IF}_{\mathrm{t}}$ & total input of the firm in time period, $\mathrm{t}$ \\
$\mathrm{OF}_{\mathrm{t}}$ & total output of the firm in time period, $\mathrm{t}$ \\
$\mathrm{TP}_{\mathrm{it}}$ & total productivity of the product, $\mathrm{i}$ in time, $\mathrm{t}$ \\
$\mathrm{I}_{\mathrm{it}}$ & current period input for product, $\mathrm{i}$ \\
$\mathrm{O}_{\mathrm{it}}$ & current period output for product, $\mathrm{i}$ \\
$\mathrm{i}$ & number of product $\mathrm{i}=1,2, \ldots \ldots ., \mathrm{N}$ \\
$\mathrm{N}$ & total number of products manufactured in the \\
& period under consideration
\end{tabular}


given by the following:

Total Productivity $=\frac{\text { Total tangible output }}{\text { Total tangible input }}$

where, Total tangible output $=$ Value of finished units produced + other income.

Total tangible input $=$ Value of $(\mathrm{man}+$ machine + material + energy + other expenses) inputs used.

Total Productivity Model (TPM) for a firm ${ }^{9}$ producing $\mathrm{N}$ independent products has been shown in the Fig. 1.

\section{Steps involved in the study}

Step-1: Conducting primary survey: A primary survey was conducted in the project area in order to have an overview of the entire production process of Engineering Workshops and to have a conception of the project area to prepare questionnaire.

Step-2: Preparing primary questionnaire: Based on the primary survey and the knowledge gathered from the literature, questionnaire was prepared. It was checked to ensure its validity.

Step-3: Verification and finalizing the questionnaire: Necessary modification was made before finalizing the

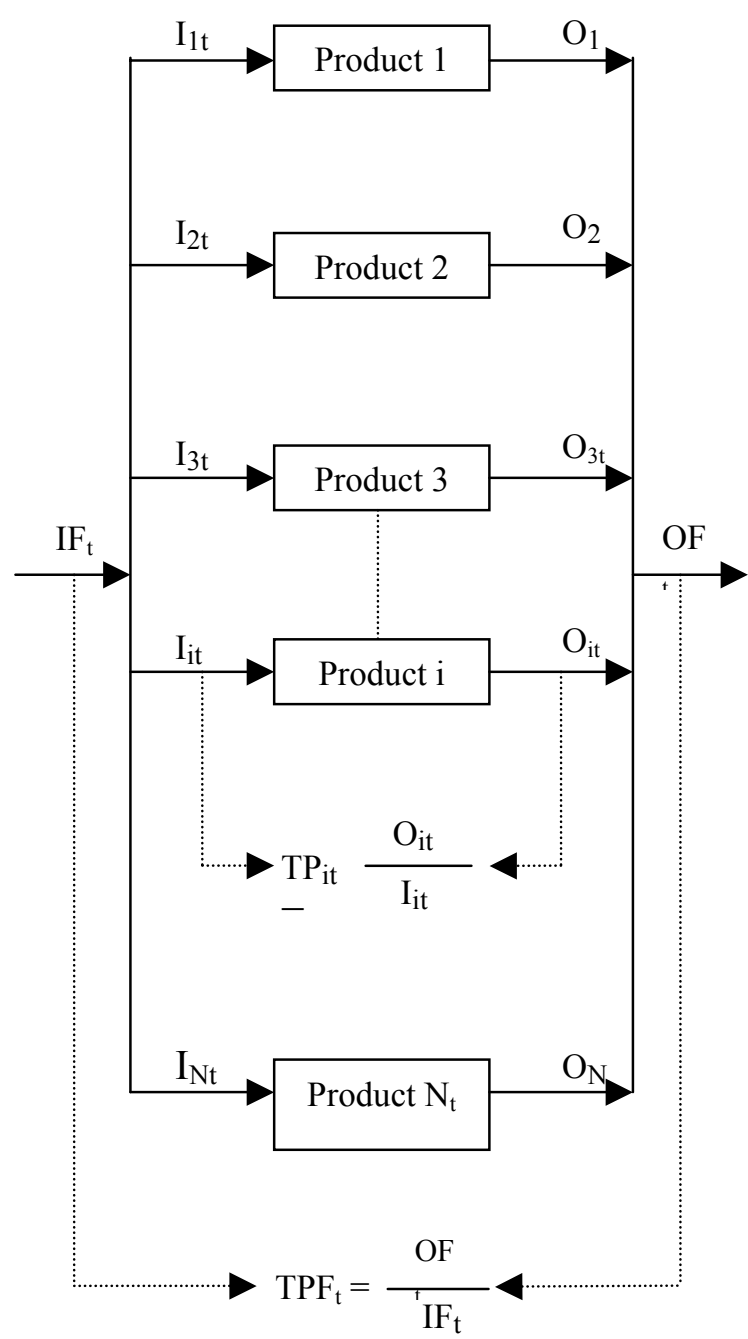

Figure 1: The basic total productivity model (TPM) for a firm and its individual products in time period $t$. draft questionnaire and questions were then arranged group-wise according to the input variables such as man, machine, material, and safety.

Step-4: Data collection: Based on questionnaire, data on the five input variables for different workshops were collected. This step also included diagnostic interviews with the owners and the individuals (welder, operator, and helper, etc.) respectively to gather some other relevant information regarding productivity.

Step-5: Data processing and analysis: In this step, the data collected from the case study were processed. Final analyses of the processed data were performed based on the Research-Model.

\section{RESULTS AND DISCUSSION}

\section{Overall Productivity and Individual Product Productivity}

Table 1 shows that the overall productivity of the workshops is much higher than unity, whereas in most cases the productivity in terms of individual products is found to be close to unity. This so happened in most of the product manufacturing cases because of inefficient utilization of material, employment of unskilled workers, and lack of suitable work environment. However, the number of sold product(s), having productivity more than unity, was found to be much higher than that of the product(s), having productivity less than unity, in various workshops. Ultimately, what all comes down to is the overall profit on selling or overall productivity of the workshops studied more than unity.

\section{Comparative Analysis}

This analysis provides the reasons behind the variation in productivity between product-to-product and workshop-to-workshop as well.

Table 1: Productivity in terms of individual product and overall productivity of various workshops.

\begin{tabular}{|c|c|c|c|c|c|c|c|c|c|c|}
\hline 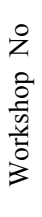 & تٓ & 寄 & $\begin{array}{l}\frac{\omega}{\mathbb{U}} \\
\text { E }\end{array}$ & 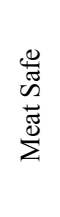 & $\begin{array}{l}\stackrel{\vec{E}}{\Xi} \\
\stackrel{0}{0}\end{array}$ & 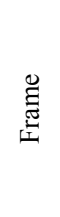 & $\underline{\Xi}$ & $\underset{\stackrel{E}{E}}{\stackrel{\vec{E}}{E}}$ & 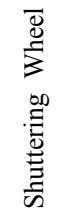 & 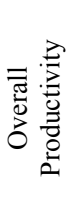 \\
\hline $\mathrm{A}$ & \begin{tabular}{|l|}
0.94 \\
\end{tabular} & 1.24 & 0.48 & & & & & & & 2.66 \\
\hline B & 1.32 & 1.66 & & 1.85 & & & & & & 4.83 \\
\hline C & 1.64 & & & 1.08 & 1.17 & & & & & 3.89 \\
\hline D & & 1.17 & & & & 1.04 & & & & 2.21 \\
\hline $\mathrm{E}$ & 1.10 & & & & & 1.23 & & & & 2.33 \\
\hline $\mathrm{F}$ & 0.78 & 1.22 & & & & 0.73 & & & & 2.73 \\
\hline $\mathrm{G}$ & 0.93 & 0.76 & & & & 0.71 & & & & 2.4 \\
\hline $\mathrm{H}$ & & 1.31 & 0.38 & & & 0.86 & & & & 2.55 \\
\hline I & 1.05 & 1.45 & & & & & 0.98 & & & 3.48 \\
\hline $\mathrm{J}$ & & 1.56 & & 1.08 & 1.05 & & & & & 3.69 \\
\hline $\mathrm{K}$ & & & & & & & & 1.15 & 0.71 & 1.86 \\
\hline $\mathrm{L}$ & & 1.28 & & & & & & 1.19 & 0.81 & 3.28 \\
\hline $\mathrm{M}$ & 0.96 & 1.32 & 1.22 & & & & & & & 3.5 \\
\hline $\mathrm{N}$ & 1.08 & 1.13 & & & & 0.99 & & & & 3.2 \\
\hline $\mathrm{O}$ & 0.93 & 1.08 & 1.25 & & & & & & & 3.26 \\
\hline $\mathrm{P}$ & 1.07 & 1.09 & & 0.65 & & & & & & 2.81 \\
\hline
\end{tabular}


Table 2: Variation in productivity in terms of product in between two workshops.

\begin{tabular}{|c|c|c|c|c|}
\hline Workshop & $\begin{array}{c}\text { No. of } \\
\text { Gates }\end{array}$ & $\begin{array}{c}\text { Material } \\
\text { cost (TK) }\end{array}$ & $\begin{array}{c}\text { Amount of } \\
\text { Material used (kg) }\end{array}$ & Productivity \\
\hline A & 12.50 & 973 & 36.75 & 0.95 \\
M & 12.50 & 932 & 35.86 & 0.96 \\
\hline
\end{tabular}

Table 3: Variation in overall productivity in between two workshops.

\begin{tabular}{|c|c|c|c|c|c|}
\hline 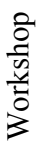 & 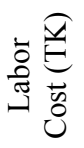 & 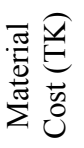 & 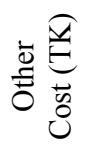 & 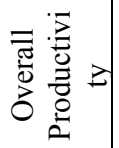 & 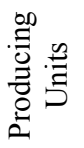 \\
\hline A & 1050 & 2370 & 391.14 & 2.66 & 4.17 \\
\hline G & 1050 & 2191 & 358.43 & 2.40 & 3.75 \\
\hline
\end{tabular}

Table 4: Variation in material productivity in between two workshops.

\begin{tabular}{|c|c|c|c|}
\hline Workshop & $\begin{array}{c}\text { Scrap } \\
\text { Produced } \\
(\mathrm{kg})\end{array}$ & $\begin{array}{c}\text { Total } \\
\text { Material } \\
\text { Used }(\mathrm{kg})\end{array}$ & $\begin{array}{c}\text { Material } \\
\text { Productivity }\end{array}$ \\
\hline $\mathrm{N}$ & 4.65 & 113.00 & 0.96 \\
$\mathrm{~F}$ & 6.73 & 122.31 & 0.94 \\
\hline
\end{tabular}

Table 5: Effect of work environment on overall productivity.

\begin{tabular}{|c|c|c|c|c|}
\hline $\begin{array}{l}\text { Working Problems } \\
\text { Faced by Workers }\end{array}$ & $\mathbf{F}$ & G & $\mathbf{H}$ & I \\
\hline Scarcity of Light & $\sqrt{ }$ & $\begin{array}{l}\sqrt{1} \\
\sqrt{ }\end{array}$ & $\sqrt{ }$ & \\
\hline Injury Problem & $\sqrt{ }$ & $\sqrt{ }$ & $\sqrt{ }$ & $\sqrt{ }$ \\
\hline Excessive Temperature & $\sqrt{ }$ & $\sqrt{ }$ & $\sqrt{ }$ & $\sqrt{ }$ \\
\hline Lack of Space & & $\sqrt{ }$ & $\sqrt{ }$ & $\sqrt{ }$ \\
\hline Productivity & 1.68 & 1.44 & 1.77 & 1.89 \\
\hline
\end{tabular}

From Table 2, it is observed that both the workshops $\mathrm{A}$ and $\mathrm{M}$ producing the equal units of gates of same dimension using the same material ( $\mathrm{Z}$ bar) differ in productivity from each other. Matter of fact, the amount of material used in workshop A was found to be more than that used in workshop $\mathrm{M}$ to fabricate the same products of equal dimensions. On the other hand, it can be explained that workshop $\mathrm{M}$ utilized the material in more optimized way that caused higher productivity gain in terms of product than that of workshop A. From Table 3, it is found that overall productivity of workshop A is more than that of workshop G, even though both the workshops have same labor cost and material cost of workshop $G$ is less than that of workshop A. This is because of higher production rate of workshop A than that of workshop G. It can also be noted that the variation of the costs other than labor and material costs cause a little impact on overall productivity.

In Table 4, it is observed that workshop $\mathrm{N}$ has a higher productivity in terms of material than workshop F, even though both the workshops $\mathrm{F} \& \mathrm{~N}$ produce the same number of products. It so happened because of higher scraps production due to technician's lack of knowledge on proper utilization of material in workshop $F$ than in workshop $\mathrm{N}$ and this, in turn, caused the lower productivity of the workshop F. This is worth mentioning that scraps produced in workshop $\mathrm{F}$ are $2.5 \mathrm{~kg}$ for gate, $2.75 \mathrm{~kg}$ for grill \& $3.0 \mathrm{~kg}$ for frame per $50 \mathrm{~kg}$ of raw material, whereas scrap production in workshop $\mathrm{F}$ is $2 \mathrm{~kg}$ per $50 \mathrm{~kg}$ of raw materials for each of products. Table 5 shows the effect of problems like scarcity of light, noise, lack of space, and excessive temperature, etc., on the overall productivity of workshop studied.

In fact, these were the common problems that the workers faced during their working period. From the table, it is evident that the more problems faced by workers during working period, the less are the overall productivity of the workshops studied. Moreover, studying such workshops as $\mathrm{F}, \mathrm{H}$, \& $\mathrm{I}$, it is found that among the problems faced by the workers, noise and scarcity of light have the most adverse effect on productivity. Again, comparing the workshops $\mathrm{H}$ and $\mathrm{I}$, it can be noted that noise is more critical to overall productivity reduction.

\section{Overall Analysis}

Overall analysis was done based on observations and the data obtained from the study. The outcomes of this analysis considered to be useful in the development of improvement strategy are as follows:

口 Workers of $75 \%$ and $62.5 \%$ workshops studied faced such problems as excessive temperature, and noise \& lack of space, respectively during working hours. Due to lack of space inside the workshops, workers are to work in the courtyard with no shedding, where the excessive sunlight makes working environment uncomfortable. This, in turn, affected adversely on productivity.

- $43.75 \%$ of the workshops possessed improper layout.

a The three categories of workers were employed in the workshops such as, welder, machine operator and helper. They were found to be mostly unskilled and having no knowledge about safety and ergonomics.

a No workshops had satisfactory number of safety equipments. Besides, most of the workers were found to be unwilling to use mask, gloves, and other safety equipments. Because, due to their smattering knowledge on safety as well as ergonomics, they thought that using safety equipments would intercept the way of doing their job.

a Possible diseases and injuries like cutting fingers \& headache due to noise, excessive temperature and dust; cutting hands; and itching, sneezing \& allergy due to dust occurred in $25 \%, 32 \%$, and $50 \%$ of workshops studied respectively. This is worth mentioning that frequent accidents and injuries occurred due to lack of safety training and inadequate use of safety equipments.

a The sultry state prevailed in the most of the workshops was due to scarcity of ventilation.

- Haphazard electrical arrangement prevailed in the workshops resulted frequent short circuit accidents and caused couple of machining or operating hours to lose. This, eventually, affected the overall productivity.

- No use of scraps to minimize the wastage of material that, in turn, caused lower productivity.

\section{IMPROVEMENT STRATEGY}

From the analysis, it is found that the weak points of the organizations studied are lack of skilled workers, improper material inventory system, improper utilization of material, lack of training facilities, improper layout, deficiencies of safety equipments, and so on. However, these weak points need to be alleviated to increase the existing level of the productivity of the small metal workshops. 
Table 6: Standard size of the products usually ordered by customers and the cost of raw material.

\begin{tabular}{|c|c|c|c|}
\hline \multicolumn{2}{|c|}{$\begin{array}{l}\text { Standard Size of Products } \\
\text { (sft/unit of product) }\end{array}$} & \multicolumn{2}{|c|}{$\begin{array}{c}\text { Cost of Raw Material* } \\
(\mathrm{TK} / \mathrm{kg})\end{array}$} \\
\hline Gate & 35 & $\mathrm{Z}$ bar & $26.0 / 26.5$ \\
\hline Grill & 17.5 & Flat bar & $19.0 / 19.5$ \\
\hline Shelf & 10 & GIPSheet & 32.0 \\
\hline Meat Safe & 15 & Coil Sheet & 26.0 \\
\hline Drum & 10 & $10 \mathrm{~mm} \operatorname{Rod}$ & 23.0 \\
\hline Shutter & 40 & & \\
\hline Shutter Wheel & 1 & & \\
\hline
\end{tabular}

Measures to be taken for improving overall conditions

To improve the overall conditions of small metal workshops, the following measures are to be taken:

\section{Improvement of inventory system}

Following inventory system improvement strategies could be implemented for two different cases:

When the raw materials shops are far away from the workshop: As per customer orders for products of different sizes, given in the Table 6 , the owners of the workshop could maintain the minimum inventory level by storing such an amount of raw materials required to fabricate three or four units of each product. This might reduce the frequent transportation cost leading to ultimate improvement of productivity.

- When the raw materials shops are available around the workshops: In this case as the raw materials are readily available, i.e. transportation cost is almost zero; the owners need not to store the materials as inventory. This zero inventories would, in turn, improve the productivity by deducting inventory cost.

\section{Enhancements of Material Utilization}

These could be done in the following ways:

a Providing vocational training to such workers as welder, and machine operators for their respective jobs. It would help the workers in effective utilization of the raw materials. However, to make the workers properly trained in a particular field, they need to have minimum secondary school education upto class VIII.

- Reusable scraps should be separated and stored according to their size so that these are readily available whenever needed. This arrangement would, perhaps, enhance the material utilization and reduce the manufacturing time as well. However, it would, eventually, improve the productivity through reduction in material cost and increase in production rate as well.

- It has to be ensured that unusable scraps are well preserved and sold time-to-time so that these cannot contaminate the environment. Moreover, the soldscraps would contribute to the productivity of the workshops by adding additional money.

\section{Improvement of the Working Conditions}

Following actions could be taken to improve the working conditions:

- Sunset could be setup at the courtyard for protecting the workers from sunlight to protect the workers from heat stroke and to reduce the fatigue caused by heat as well.
Energy saving rod light could be used instead of bulb as the bulb generates less light and more heat causing the workers' drowsiness and consume huge power contributing to higher electricity bill generation. It may be noted that using rod lights instead of bulbs in shedding system would increase initial investment. However, in long run, it would be profitable in terms of improvement of work environment and the power consumption as well.

- Fencing of revolving machinery (for instance, casing of grinding wheel of a grinder) could be used to avoid the offensive incidence and ultimately to reduce the cost of injuries and accidents.

\section{Improvement of the Safety Awareness}

Following safety awareness actions could be taken to reduce the safety-related cost:

- Periodic discussion on safety instruction could be arranged either in a week or in a month.

a The owner of the workshop could monitor the workers if they take safety measures or not during working hours.

- The workshop owners' association could take an initiative to improve their workers' skill through providing proper training. To arrange the training for their workers, association could make agreement with the local vocational training institutes.

\section{CONCLUSION}

It has already been mentioned that the study was conducted taking some parameters into considerations with a view to get overall picture of the Engineering Workshops studied. While conducting the study, some weak and strong points of those studied workshops were identified. The highlighted weak points identified during study are lack of skilled workers, improper utilization of materials, improper material inventory system, inadequate safety equipments, lack of safety training, and so on. On the other hand, the positive aspects of these workshops are employment generation, spare parts production that contributes a lot to the manufacturing units, etc. From our observation, it is clear that if the weak points identified could be alleviated by implementing the improvement strategy made, the existing level of productivity of the workshops would increase. This would, eventually, contribute to a large extent to the development of socioeconomic condition of the country through their more contribution to national GDP and more employment generation as well.

\section{ACKNOWLEDGEMENT}

The authors are grateful to the Department of Industrial and Production Engineering, SUST, for providing the administrative and financial support to carry out this research.

\section{REFERENCES}

[1] ITDA "Environmental Impact Assessment of Small Metal Workshops", Intermediate Technology Development Group (ITDA), Bangladesh, 1996.

[2] Khisa and Prodipta, 2000, "A Case Study Research on Contribution of Local Workshops in the Tea Garden of Bangladesh, Engineering News, pp. 10-13, October 06. 
[3] Hussain, K., 2003, "Effluent Bangladesh" published in "the Daily Sangbad", pp. 07, July 15.

[4] Al-Darrab, Ibrahim A., 2000, "Relationships between Productivity, Efficiency, Utilization, and Quality", Journal of Work Study, Vol. 49(3), pp. 97-104.

[5] Kao, C., Chen, L-H., Wang, T-Y. and Horng, S. K. SD., 1995, "Productivity Improvement: Efficiency Approach vs Effectiveness Approach" Journal of OMEGA, Vol. 23(2), pp.197-204.

[6] Ahmed, S., Hassan, M. H. and Taha, Z., 2005, "TPM Can Go Beyond Maintenance: Excerpt From a Case Implementation", Journal of Quality in Maintenance Engineering, Vol. 11(1), pp.19-42.
[7] Behrens, R. and De Haen, H., 1980, "Aggregate Factor Input and Productivity in Agriculture: A Comparison for the EC-member Countries", Journal of European Review of Agricultural Economics, Vol. 7(2), pp.109-146.

[8] Propkopenko, J., 1987, "Productivity Management: A Practical Handbook", ILO Publications, CH-1211 Geneva, $1^{\text {st }}$ ed., pp. 23-31.

[9] Sumanth, D.J., 1984, "Productivity Engineering and Management", McGraw Hill Book Company, New York, pp.153-159. 